\title{
The Roots of the Challenge: Undergraduate Chinese Students Adjusting to American College Life
}

\author{
Mei-Ling Tung ${ }^{1}$ \\ ${ }^{1}$ School of Education, Saint Louis University, Saint Louis, MO, USA \\ Correspondence: Mei-Ling Tung, School of Education, Siant Louis University, Saint Louis, MO, USA. Tel: \\ 1-314-977-2330. E-mail: mtung1@slu.edu
}

Received: July 10, 2016

Accepted: August 1, 2016

Online Published: August 5, 2016

doi:10.5430/ijhe.v5n3p121

URL: http://dx.doi.org/10.5430/ijhe.v5n3p121

\begin{abstract}
Recent economic development in China not only has improved the overall living standards of Chinese people, but it has also created a new middle class. Another impact of the economic development is the increasing demand for educated workers. Subsequently, the demand for quality higher education has also increased. With more than $50 \%$ of the world's top 100 universities located in the United States, the United States is regarded as the number one destination for international students for higher education. Due to the cultural differences between China and the United States, scholars have found that Chinese students encounter the most challenges adjusting to American college life. Lack of Western cultural exposure, different cultural values, the effect of the One-Child Policy, the emphasis on effort, endurance, and hard work in education, the continual impact of the Cultural Revolution's aftermath on people's relationships, the unfulfilled expectations of American college life experiences, and the influence of the Chinese education structure on students' characters and skills-building all have an impact on Chinese students' worldview and their interaction with their new environment. By reviewing the literature on the topic, this article seeks to understand the roots of the challenge to gain insight into the reasons why Chinese students do what they do after they come to the United States for higher education.
\end{abstract}

Keywords: Adaptation, Chinese students, Cultural differences, Integration, International students

\section{Introduction}

As a result of the economic development in China in the past three decades, the overall living standards for Chinese people have improved, a new middle class has been created, and the demand for highly educated workers has also increased. The improved living standards create new demands. The new demands require new talents and expertise. Employers thus are willing to offer competitive salaries and benefits to attract educated and competent professionals to provide services to meet the ever-increasing needs. Individuals and families recognize that education is an investment that helps secure higher income and social status; the subsequent change from the classic conception of education as consumption to education as investment was inevitable. The increased value of a college education created demand for high quality college education ( $\mathrm{Gu}, 2012)$.

Higher education reform and expansion from both public and private sectors in China provided more students with opportunities to pursue higher education. Student enrollment in Chinese universities increased fivefold between 1998 and 2005. The annual growth rate was $20 \%$ in 2007 and is expected to be $50 \%$ by 2050, while the total enrollment in higher education in China is projected to be 40 million in 2020 (Ho, 2010). Since 2007, when former Premier Wen Jiabao pledged a $42 \%$ increase in national education spending (Pan, 2007), the challenge for higher education institutions in China continues to be a shortage of funding to handle the growing student population.

Additionally, the demand for individuals of various talents to engage in business surged due to the rapid economic development in China. The average monthly salary for a mid-level manager in one of the major cities in China is three times that of a full professor (Yang, 2008). It is thus difficult for higher education institutions in China to compete with the private sector for hiring qualified faculty members to teach college courses. To respond to the shortage of faculty, many institutions use young teachers who might have a graduate degree but who have limited real-world experiences. In addition to a shortage of funding and a lack of qualified faculty members, the quality of education is not satisfying, as most institutions continue to use outdated teaching methods and materials to facilitate students' learning experiences (Yin, Lu \& Wang, 2014). One other challenge for higher education institutions in 
China is a lack of creativity (Chen, 2014). While research by Sofo (2005) determined that Chinese business leaders were as creative and independent as their Western counterparts, Chinese educators continued the norm of accepting existing rules and decisions. These educators are thus not able to keep up with the new demands caused by economic development. Many Chinese parents who have been successfully engaged in the business field have recognized the need for their children to have access to high quality college education in order to become competitive for better employment or business opportunities in the future. With the increased business interaction between China and the United States, and with the wave of Chinese graduates who have returned from the United States to China with U.S. degrees (enabling them to obtain better employment with foreign companies based in China), Chinese parents have the opportunity to learn about the differences between the Chinese and U.S. higher education systems. Many Chinese parents realize that the higher education system in China is not the best option for their children. Studying abroad becomes a preference for students whose parents have the financial resources to send their children to another country. Another concerning matter for higher education in China is that many Chinese students are not prepared for college. Prior to the reform in higher education, high school students who did not perform well on the Annual College Entrance Examination had to find other options, such as vocational schools or employment. Education reform opened access to higher education for students who would not otherwise have been admitted to a college or university. With the combination of low education quality and unprepared college students, a Chinese college diploma no longer guarantees employment in China (Yang, 2008).

Higher education in the United States is frequently perceived as being the best in the world; therefore, it quickly became the most popular destination for Chinese students seeking an undergraduate education (Chen, 2014). The number of Chinese students coming to the United States for higher education has grown from 28 in 1978 to approximately 304,010 in the 2014-15 academic year (Open Doors, 2016). These statistics, combined with projections of an increase in this population and an acknowledgement of the economic contributions they make to the U.S., requires that university administrators and educators understand the unique needs of this student population so as to enhance their educational experiences. Furthermore, studies indicated that while Asian students encounter more challenges adapting to American college life compared with their European counterparts, Chinese students face even more obstacles when it comes to adaptation compared with other Asian student groups. Therefore, it is important to address Chinese students' cultural and psychological adaptation to their new life in the United States (Özturgut\& Murphy, 2010). The following section will describe key characteristics of Chinese students as a first step toward understanding their unique needs.

\section{Chinese Students and the Pursuit of Higher Education}

With the United States being the number one destination for Chinese students to pursue higher education outside of China, Chinese students from Mainland China represent the largest group of international students in the United States. These students perceive the quality of overseas education as the most important reason to study abroad; pursuing advanced studies is the main goal for Chinese students (Griner\&Sobol, 2014). Gaining understanding of other countries and cultures to become global-minded citizens is another factor that influences Chinese students' decisions to study abroad (Griner\&Sobol, 2014). Improved job prospects and life enrichment are other benefits of studying overseas (Chen, 2014). Other studies (e.g., Hagedorn \& Hu, 2014; Griner\&Sobol, 2014) have indicated that social status is another factor that inspires Chinese students' decisions to study abroad.

\section{Characteristics of Undergraduate Chinese Students}

Since the implementation of economic reform and the Open Door policies in 1978, China has enjoyed fast-growing economic development. China replaced Japan as the second-largest economy in the world in terms of GDP in 2010. As a result, individuals' income levels and demands for more accessible and higher quality education also increased (Yue, 2015). In 2010, the higher education entrance rate reached $30 \%$ compared to less than $15 \%$ before the education reforms of 1999 (Yue, 2015). The expansion of higher education increased student enrollment, but the pressure of doing well on the exam for admission to top universities remained. This exam, which students must take to be admitted to Chinese colleges and universities, is known as the National College Entrance Examination. Students are then placed in higher education institutions based on their entrance exam scores. Students with top scores are placed in state-funded public schools, such as Peking University and Tsinghua University. Students who do not perform as well are placed in second-tier, third-tier, or private institutions, which are viewed as being much less desirable than the state-funded public schools (Ertl\& Yu, 2010). It is commonly believed that students who graduate from top public schools are far more favored in the job market and that they are guaranteed to have brighter futures (Hu \& Hagedorn, 2014). As a result of this pressure, according to China's Huran Report (2010), 85\% of parents with financial means choose to bypass the entrance exam by sending their children to study overseas. 
Additionally, studying overseas is perceived as another option for parents whose children may not be accepted by the top colleges and universities in China (Chen, 2014).

Another important factor unique to Chinese students is the effect of China's One-Child Policy (OCP), which affects how Chinese students perceive themselves. Since the implementation of the OCP in 1980, the majority of Chinese students enrolled in colleges have been the only child in their families. These children grew up in a family consisting only of adults (parents and grandparents), with no other siblings. Thus, these only children received all the love and attention of the adults without competition from siblings, leading many to develop a self-centered mentality. Socialists refer to this social phenomenon as the Little Emperor Syndrome. The Little Emperor Syndrome is an effect of the OCP. Scholars indicated that the OCP has produced individuals of the following characters: significantly less trustworthy, less conscientious, less trusting, less competitive, more risk-averse, and more pessimistic (Cameron et, al., 2013; Cosgrove, James \& Zhao, 2015) They are used to being waited on and protected by adults (Hu \& Hagedorn, 2014). Furthermore, the OCP created a generation of parents with extremely high expectations for their only children (Hu \& Hagedorn, 2014). Because of their embrace of elite education, Chinese parents believe that if they are involved with their children's day-to-day learning and activities, it will increase the chance for their children to perform better at school. Under the influence of Confucian values, Chinese parents and educators place less value on natural ability than on effort; this is in contrast to American parents and educators, who put more value on natural ability. Beliefs like these permit Chinese schools to have extremely rigorous curricula to make sure that students work hard to prepare for entrance exams. Starting at a young age (before kindergarten), children have been expected to learn basic math concepts and to participate in after-school programs to obtain other skills deemed crucial for getting ahead of other students. In addition, all children are put under constant pressure engage with schoolwork because of the traditional Chinese emphasis on education, a result of the Confucian legacy, too. For example, starting in elementary school, students have hours of homework each day. Due to these high standards, children who perform well at school bring glory to their families, while extracurricular activities are perceived as useless among Chinese parents. For example, helping with household chores, participating in athletic events and being involved in the community are not considered worthwhile because Chinese colleges and universities do not evaluate these factors for admissions. Chinese students are expected to be in a constant study mode, at school and at home. Students who do not perform well are perceived as being lazy (Thakkar, 2011). Parents thus believe that they need to push their children to study as much and as hard as possible so that they can succeed academically, regardless of natural ability. Students are not given opportunities to learn any daily living skills (such as cooking, doing laundry, or cleaning) but instead, are expected to learn study skills before they come to the United States (Chen et al., 2011). In order to provide an environment where students are focused on schoolwork without disruptions, schools and parents make decisions without input or consent from students. Chinese students are used to accepting decisions from authorities without being involved in the decision-making process (Chen et al., 2011). This phenomenon continues until children graduate from college. Not surprisingly, parents have the greatest influence on undergraduate Chinese students' decisions to study overseas (Chen, 2014; Wang, 2015). With Chinese students not provided with opportunities to learn skills deemed important to help them transition into young adulthood, their lack of life skills makes it a lot more challenging for them to become adjusted to American colleges, where people expect students to be independent individuals and assume that they are capable of taking care of themselves.

The annual entrance exam is the major method that Chinese universities use to differentiate among students' qualifications for higher education; thus, high school grade point average (GPA) is not perceived as an indication of students' academic performances or as recognition of their abilities to engage in sustained school work. Therefore, a common practice for obtaining a high school academic transcript for U.S. college admissions allows Chinese students to fill out the transcripts with their preferred grades by themselves and with endorsement from their schools - thus permitting them to meet the academic requirements of any college's admissions criteria (Muth, 2015). High school transcripts thus do not reflect these students' academic strengths or weaknesses. Furthermore, many Chinese students choose to study abroad to avoid the stress of competing in the Annual Entrance Examination or to avoid the embarrassment of being placed at a third-tier university or private institution (Chen, 2014). As a result, many of these students do not have the required study skills to uphold the academic expectations that American higher education institutions set for their students.

The language barrier remains the biggest challenge for Chinese students. Most colleges and universities in the United States require students to obtain a certain score on the Test of English as a Foreign Language (TOEFL) or the International English Language Testing System (IELTS) test to be admitted; for example, a score of 80 on TOEFL or 6.0 on IELTS is considered proficient, while a score of 55 on TOEFL or 5.5 on IELTS requires placement in English as a Second Language (ESL) classes. These scores help colleges and universities identify students' English proficiency 
skills. The challenge schools face is that "TOEFL/IELTS-exam cram schools," as they are often known, are widely available in China (Doe \& Fax 2011; Ma, 2013). Students who plan to study overseas enroll in these schools to learn techniques to prepare for the TOEFL or IELTS tests without necessarily understanding the content. Scholars have found that students who are less fluent in English are more likely to participate in the "TOEFL/IELTS-exam cram schools" (Gan, 2009). Students with high TOEFL scores therefore do not necessarily possess the necessary English proficiency skills required to perform in English-language higher education settings.

"Play as much as you want for four years" is a well-known phrase among Chinese college students, because students believe they do not have to worry about schoolwork and that they will get their diploma at the end. All the effort and emphasis on education is focused on passing the entrance exam. Life gets easier after students are enrolled in colleges. Big lecture hall settings discourage instructors from keeping track of student attendance. Plagiarism and cheating during exams are common among Chinese college students, as well (Ma, McCabe \& Liu, 2013). Students are graded based mostly on midterm and final exams (Wolff \&Qiang, 2011). As a result of these phenomena, Chinese students' college graduation rates remains high compared with those of American college students (Ross, Chen, \& Zhou, 2011). In contrast with American college education, where creativity, initiative and independent thinking are perceived as necessary skills to be successful in college, Chinese college students rely on lectures and notes as their sources of information to pass exams for grades (Rajaram, 2013). Chinese students who choose to study abroad expect to have a similar, relatively easy college experience; they have little understanding of the academic rigor of higher education in the United States, especially at the top U.S. universities. They tend to overlook the importance of the syllabus and are more likely to disregard attendance without realizing that attendance and participation in class affect their grades at the end of the semester. New students, in particular, have the misconception that passing the midterm and final exams will be enough to get good grades. Low grades and academic probation are often the result of consistent absences. The academic expectations in American higher education are very different from those in Chinese universities and colleges. Chinese students lack understanding of these expectations, which makes it more challenging for them to achieve academic success (Edna \& Rawlings, 2013).

Many Chinese students come to the United States with the goal of becoming competent in Western culture and finding business opportunities for their family (Zhang \& Xu, 2007; Chen, 2014). They start their journey to the United States for higher education with great enthusiasm and little anticipation of the challenges they might encounter as international students. Chinese students often find themselves feeling inadequate and isolated in social settings due to their lack of understanding of American culture; for example, two of the most popular American sports, football and baseball, are not well-known in China. Chinese students without exposure to those sports are not able to participate in conversations about them. Not being able to participate in or understand conversations creates a sense of embarrassment and boredom (Hegarty et al., 2014). Furthermore, many of the American social norms are foreign concepts to Chinese students; not surprisingly, social isolation is one of the most difficult areas of adjustment for international students and Chinese students are not unique in this regard (Yan \& Berliner, 2013). This has historical roots in Chinese culture, particularly in agriculture. Labor-intensive agriculture in rice paddies requires people to stay in one place throughout the year to sow and harvest. Chinese people thus became used to staying in one place without moving for their entire lifetimes. As a result, Chinese people view relationships quite differently than Americans do. It is customary for Chinese people to take time to learn about each other and to become acquaintances or friends. American culture, on the other hand, has been based on mobility since its beginnings. The spirit of adventure and exploration of the unknown are embedded in American culture. Additionally, the invention of the automobile also made it possible for Americans to move to different places for employment and other opportunities without much effort. This mobility makes it necessary for Americans to be able to become connected with people in a relatively short period of time. The ability to mingle with confidence and to initiate small talk is thus a social skill that most Americans acquire. The way Chinese people socialize with each other is mostly in the form of a dinner banquet. Chinese people eat and drink at the dinner table to become friends and to close business deals. To be in a setting where mingling and small talk are expected is a challenge for Chinese students (Verstappen, 2015). Personal boundaries are another challenge for Chinese students. It is common for Chinese people to share information that Americans would consider private, such as household income or marital status. To Chinese people, closeness means something quite different from what it means to Americans, too. In China, it is an indication of closeness to allow friends to enter one's bedroom without asking for permission first. Courtesy expressions, such as "please," "thank you," and "sorry," are not only rarely used in daily Chinese life but are not appreciated by close friends and family members because Chinese people perceive polite expressions as an indication of distance between individuals. These expressions, however, are valued and expected in American culture (Li, Canziani \& Hsieh, 2016). These different perceptions of friendship and closeness make it difficult for Chinese students to know how to build 
relationships with their American peers. What American students perceive as privacy, Chinese students perceive as disengagement. American students, on the other hand, might feel as if their privacy is invaded by Chinese students' ways of showing affection. Chinese students have a harder time building up social networks in campus communities, consequently they congregate with each other as groups, which adds further to their isolation from the mainstream culture.

Most Chinese students in the United States come from cities of several million people. For instance, based on the Country Population Statistics of 2016, it was estimated that over 20 million people resided in Beijing, close to 24 million in Shanghai, and 27.7 million in Chongqing, a city in central China (Country Population, 2016). Students who grew up in big cities are used to city life, including big shopping malls, movie theaters, and restaurants. In the United States, many colleges and universities are located not in large cities but in rural areas; examples include Michigan State University and Truman State University. Chen (2014) indicated that $44 \%$ of students choose schools based on "the location of the institution" (p. 5). Rural life is neither appreciated nor valued in Chinese culture. For example, farmers are looked down upon because they live in rural areas. Chinese people often use the word "farmer" to describe those who display less desirable behaviors or who are less educated. In addition to these embedded cultural values, Chinese students also possess a biased image of American life. Most Chinese students learn about American culture through magazines, movies, and TV programs (just like other people from around the world do). The images of high-rise buildings and life in glamorous cities like Los Angeles are instilled in their minds. Chinese students' expectations of American life are thus aligned with metropolitan lifestyles. One of the first culture shocks that Chinese students experience is when they learn that the location of their school limits their access to entertainment, which they expect to have as part of urban living. To live in a small town without access to high-end shopping malls and good restaurants is a big adjustment for many Chinese students. For instance, St. Louis is a city of 2.8 million inhabitants, and has a rich urban culture, yet Chinese students refer to St. Louis as a "village" based on the Chinese definition of a city. Being in an even smaller city or a rural area means that not only are students put out of their comfort zones but that they now have limited access to familiar sources of entertainment leading to opportunities to socialize (Poyrazl\& Grahame, 2007). All these changes are imposed upon Chinese students as soon as they arrive on their college campuses, which cause homesickness and make adaptation more challenging for these students than it does for other international students who may have grown up in countries where rural living is more valued.

Under the Chinese government's policies, civic engagement has to be affiliated with and supervised by the government. A study conducted by Li (2009) revealed that $85.9 \%$ of Chinese college students reported to be most actively involved in the Chinese Communist Party (CCP) organizations among all co-curricular organizations on Chinese college campuses. It is a way for college students to increase their chances of being accepted to the CCP, which increases their upward mobility to leadership positions in state hierarchies and managerial positions in state-run organizations after graduation (Simon et al., 2009; Afridi, Li \& Ren, 2015). Involvement on American college campus, on the other hand, does not provide such incentives for Chinese students. Many Chinese students do not see the value of being engaged in their campuses' communities. Parents see activities unrelated to academic performance as useless to their children's futures, and thus discourage their children from participating in student associations or clubs. Students and parents are not aware that campus involvement tends to increase students' overall satisfaction and academic success (Liu, Liu, \& Chi, 2014; Tu, 2011).

During the era of the Cultural Revolution (1966-1976), Chinese people were pitted against one another as a way to show their loyalty to the Communist Party - even among family members and close friends. The concept of trust was destroyed (Plänkers, 2011). The impact of the Cultural Revolution - this distrust of others - continues into the twenty-first century (Walder \& Su, 2003). Scholars regard China as a society where individuals do not place trust in non-family members (Redding, 1995; Tang, 2005). Moreover, in contrast to the 300 million people in the United States, China has a population of 1.36 billion (Central Intelligence Agency, 2016). With this many people, the level of competition is compounded, and further intensifies distrust among people. As a result of this mindset, Chinese students use fewer student services than their counterparts when issues arise; they tend to isolate themselves and avoid seeking help from school authorities (Ellis-Bosold, 2013).

Chinese attitudes towards luxury spending can be traced back to Confucius, who believed the root of social conflict and unrest is a result of uneven distribution of wealth and who viewed luxury spending as a way to distribute wealth (Peng $\&$ Chang, 2012). A luxury brand is considered as a symbol of social classification and group affiliation, which reinforces social image and self-presentation attitudes (DeBono, 2006). Collectivism as an embedded cultural value has a great impact on how Chinese people perceived their individual personalities. To seek individuality, Chinese people are more likely to self-monitor and display a stronger self-presentation attitude to show their individuality and 
social standing. Possession of luxury brands thus is considered as a social function for Chinese people, especially for those of a higher social status (Lee, et al, 2004; Li, Robson, \& Coates, 2013). Moreover, peer acceptance, perception, social impression and approval affect people's intention and willingness to purchase luxury brands ( $\mathrm{Li}$, Robson \& Coates, 2013). The Open Door policy has changed China into a consumer society, a result of its fast growing economic development. Luxury brands are perceived as being for the affluent, and help individuals enhance self-esteem. This feeling of being special has a great impact on Chinese people's spending behaviors. Chinese students who have grown up in a society where luxury goods are viewed as a symbol of prosperity are more likely to embrace the same values and behaviors. Chinese students thus are inclined to seek fulfillment from purchase of luxury brands (Durvasula\&Lysonski, 2010; Ku, Dittmar\& Banerjee, 2014). One of the phenomena is the purchase of luxury cars among Chinese college students when they come to the United States for higher education (Higgins, 2013). Another culture factor that influences Chinese people's consumer behavior is the appreciation of tangibles over intangibles, which creates other phenomena among Chinese students: Chinese students are more likely to drive luxury cars without car insurance or spend money on luxury goods while neglecting the importance of health insurance (Hoare \& Butcher, 2007).

\section{Challenges Encountered by Chinese Students in the U.S. Universities}

Many researchers have indicated that there is an association between students' stress levels and the distances from their home countries. The farther away a student's home country is from the United States, the bigger the difference is between American culture and a student's home culture. Cultural distance is considered one of the most significant factors in the intercultural adaption process (Özturgut \& Murphy, 2010; Yan \& Berliner, 2009). Other researchers have suggested that Asian students experience more challenges in the intercultural adaption process than their European peers (Heggins \& Jackson, 2003; Toshitaka \& Laird, 2014). When there is a large cultural distance between the home region and the host country, it imposes stress on the students to produce more "appropriate behaviors" to adjust to the new environment. For Chinese students, the cultural distance between America and China is quite large. The influence of Confucian philosophy makes it necessary to restrain individuality in order to maintain harmony. As a result, Chinese people value collectivism, and devalue individuality, including their own; these students find it hard to understand the American ideal of individualism. American people, on the other hand, highly value individualism and assertiveness in interactions with others. For Chinese students, in addition to the typical language barriers, communication is made more stressful when they come into contact with American people who value assertiveness over accord and harmony in human relationships. Chinese students feel intimidated by the way American people communicate with them, and they are not able to produce appropriate responses to their counterparts when certain situations arise. Another challenge for Chinese students is that Chinese culture does not praise openness or self-expression whereas American culture does. These differences between Chinese and American cultures create a lot of frustration due to miscommunication and make it difficult for Chinese students to feel confident when communicating with Americans (Sims, et al., 2015).

The perspectives of individualism and collectivism also indicate major differences between American and Chinese culture. Individualists tend to have many relationships of low intimacy and to have more in-groups that they enter and exit with greater frequency than collectivists do. Collectivists tend to have fewer but more intimate relationships (Yu \& Wang, 2011). In sum, China is a highly collectivistic nation, and the United States is a highly individualistic country. This difference between American and Chinese culture makes it more challenging for Chinese students to become integrated into American college life. As Chinese students become more exposed to American culture, tradition, values, and norms, they experience more conflict as they continue to try to function between the different worldviews of their own culture and that of the U.S. Such cultural differences make it even harder for Chinese students to become integrated through the acculturation process (Yu \& Wang, 2011). In addition to cultural differences, Chinese students also face political tension due to the difference between China's autocratic, communist system and America's democratic, capitalist system (Tsai, et al., 2016). These differences impose confusion, frustration, and stress on Chinese students as they try to navigate their new environments (Bai, 2016). Because of the cultural differences between China and the United States, Chinese students tend to experience high levels of cultural shock, which results in feelings of homesickness, loneliness, depression, and stress; in turn, this prevents Chinese students from successfully adjusting to American college life. While studies have indicated that interaction with American students increases international students' cross-cultural competency skills and helps them to become better adjusted, Chinese students tend to have less interaction with American students than other international students have (Yao, 2016).

Another challenge that Chinese students encounter is that they are expected to take initiative in their learning in the United States. This contrasts with Chinese students' preferences for hierarchical human relationships, which are 
emphasized in Chinese culture. Everyone has a role in society, and everyone is expected to understand his or her role and to behave accordingly. It is regarded as a way to maintain harmony in society. Chinese students thus are expected to show respect to authority figures and elders. They view their academic advisors and professors as authority figures, and therefore accept rules and statements from them without question and tend to wait submissively for their academic advisors or professors to provide them with instructions to move forward with their learning (Longerbeam, DeStefano \& Yu, 2013). As Charles and Stewart (1991) put it, "international students may be more dependent, demanding, or both, believing that advisors or professors should show, tell, or even do for them that for which they would be expected to assume individual responsibility in this culture" (p. 178).

Compared to American students, Chinese students are considered more reserved. Chinese students are not encouraged to share their thoughts and ideas in classroom settings, nor are they encouraged to ask questions (Chu \& Walters, 2013). Those behaviors are considered to be interruptions from the Chinese instructors' standpoint. Chinese instructors are perceived as authority figures who have the power to decide how they want to facilitate students' learning experiences. This teacher-centered and exam-based pedagogy is a common practice in higher education in China, and it sharply contrasts with the student-centered educational approach in the United States (Ho, 2010). Chinese students are not used to American methods of teaching and learning, and they tend to remain silent in class to avoid embarrassment caused by making mistakes in front of their classmates (Jacob, 2001; Zhang \& Xu, 2007). Evaluation and feedback from students to instructors are not the norm in China, and classroom participation is a foreign concept for Chinese students, too. Moreover, Chinese students are not used to following a syllabus, so they tend to overlook the importance of this document, not realizing that it defines the expectations regarding coursework (Thakkar, 2011).

\section{Conclusion}

While three in one international students were from China during the 2014-15school year, it is expected that the influx of Chinese students coming to the United States for higher education will continue to grow, particularly for undergraduate programs (Open Doors, 2016). The presence of Chinese undergraduate students on American college campuses is inevitable. With the combination of all the cultural factors that discourage Chinese students from being engaged in American colleges, educational institutions that host Chinese students need to think about ways to break down those barriers to help Chinese students understand the differences between American and Chinese cultures. Only when students have a chance to learn what they do not know will there be a chance for them to unlock the unknown and to be ready to embrace the differences. Understanding and accepting these differences is the first step for Chinese students to adapt to American college life. As Chinese students continue to choose the United States as their higher education destination, the need to understand and address Chinese students' needs, such as the challenges they face in the adaptation process and the services they require to become adjusted, also grow. Considering the number of Chinese students enrolled in American higher education institutions and how the dissimilarity of American and Chinese cultures influences Chinese students as they move toward intercultural competency, it is imperative for student services professionals to think beyond the typical linguistic difficulties and cultural adjustment challenges. Razek and Coyner (2011) suggested that it is necessary for personnel engaged with student services to understand the needs of individual international student groups and to develop realistic programs and information sessions to help students move toward intercultural competency instead of treating all international students as a homogeneous group regardless of their countries of origin. The need for more program development based on the needs of Chinese students to help them gain understanding of the general cultural and social norms in American colleges and American society as a whole is immense.

\section{References}

Bai, J. (2016). Development and validation of the Acculturative Stress Scale for Chinese College Students in the United States. Psychological Assessment, 28, 443-447. http://dx.doi.org/10.1037/pas0000198

Chen, J. (2014). An Empirical Investigation on Chinese High School Students' Choice of Pursuing Undergraduate Education Abroad. Journal of International Education and Leadership, 4(2), 1-11.

Chen et al., (2011). Parental Expressivity and Parenting Styles in Chinese Families: Prospective and Unique Relations to Children's Psychological Adjustment. Parenting: Science and Practice, 2011(11), 288-307. http://dx.doi.org/10.1080/15295192.2011.613725

Charles, H. \& Stewart, M. A. (1991). Academic Advising of International Students. Journal of Multicultural Counseling \& Development, 19(4), 173-181. http://dx.doi.org/10.1002/j.2161-1912.1991.tb00554.x 
Chu, Y. \& Walters, L. M. (2013). The question-asking behavior of Asian students in an American university classroom.Journal of English as an International Language, 8(2), 10-29.

Country Populations 2016. (n.d.). Retrieved July 09, 2016, from http://worldpopulationreview.com/countries/ Data | Center for Disease Control. (n.d.). Retrieved May 04, 2016, from https://data.cdc.gov/

DeBono, K. G. (2006). Self-Monitoring and Consumer Psychology. Journal of Personality, 74(3), 715-738. http://dx.doi.org/10.1111/j.1467-6494.2006.00390.x

Doe, C. \& Fox, J. (2011). Exploring the testing process: Three test takers' observed and reported strategy use over time and testing contexts. Canadian Modern Language Review, 67, 29-54. http://dx.doi.org/10.3138/cmlr.67.1.029

Durvasula, S. \&Lysonski, S. (2010), Money, money, money - how do attitudes toward money impact vanity and materialism? - the case of young Chinese consumers, Journal of Consumer Marketing, 27(2), 169 - 179. http://dx.doi.org/10.1108/07363761011027268

Edna, S. \& Rawlings, M. (2013). Preparedness of Chinese Students for American Culture and Communicating in English. Journal of International Students, 3(1), 29-40.

Ellis-Bosold, C. (2013). A Need Assessment: A study of Perceived Need for Student Health Services by Chinese International Students. College Student Journal, 47(1), 155-169.

Erienawati, S. (2013). Internationalisation of Higher Education Curriculum: The Contribution of InternationalStudents. Globalisation, Societies and Education, 11(3), 359-378. http://dx.doi.org/10.1080/14767724.2012.750477

Ertl, H. \& Yu, K. (2010). Equity in Access to Higher Education in China: The Role of Public and Nonpublic Institutions. Chinese Education \& Society, 43(6), 36-58. http://dx.doi.org/10.2753/CED1061-1932430602

Foreign Trade. (n.d.). Retrieved July 09, 2016, from https://www.census.gov/foreign-trade/balance/c5700.html

Gan, Z. (2009). IELTS preparation course and student IELTS performance: A case study in Hong Kong. RELC Journal: A Journal of Language Teaching and Research, 40(1), 23-41. http://dx.doi.org/10.1177/0033688208101449

Griner, J. \&Sobol, A. (2014). Chinese Students' Motivations for Studying Abroad. The Global Studies Journal, 7.http://dx.doi.org/10.18848/1835-4432/CGP/v07i01/40893

Gu, J. (2012). Harmonious expansion of China's Higher Education: a new growth pattern. Higher Education, 63(4), 513-528. http://dx.doi.org/10.1007/s10734-011-9455-6

Hagedorn, L. S. \& Hu, J. (2014). Eater Dreams: Alternative Pathways for Chinese Students Pursuing Baccalaureate Degrees in the United States. College \& University, 89(4), 75-82.

Hegarty et al., (2014). An Investigation On Whether Or Not Chinese Students Have Achieved Their Expectations to Study in U.S. Universities. International Journal of Education Research, 9(1), 163-176.

Higgins, T. (2013). Chinese students major in luxury cars. Retrieved July 09, 2016, from http://www.bloomberg.com/news/articles/2013-12-19/chinese-students-in-u-dot-s-dot-boost-luxury-car-sales

Ho, R. (2010). Assessment of Chinese Students' Experiences with Foreign Faculty: A Case Study From A Chinese University. Journal of Teaching in International Business, 21(3), 156-177.http://dx.doi.org/10.1080/08975930.2010.504461

Hoare, R. J. \& Butcher, K. (2008). Do Chinese cultural values affect customer satisfaction/loyalty? International Journal of Contemporary Hospitality Management, $\quad 20(2), \quad$ 156-171. http://dx.doi.org/10.1108/09596110810852140

Hu, J. \& Hagedorn, L. S. (2014). Chinese Parents' Hope for their only children: A transition program case study. Journal of College Admission, 2014 spring, 35-42.

Hurun Report Sheds Light on Chinese Elite. (2010). Retrieved July 10, 2016, from http://www.luxury-insider.com/luxury-news/2010/04/2010-hurun-report-sheds-light-on-chinese-elite

Inoguchi, T. et al., (2005). Values and life styles in urban Asia: A cross-cultural analysis and sourcebook based on the AsiaBarometer survey of 2003. Tokyo: Institute of Oriental Culture, University of Tokyo.

Jacob, E. J. (2001). Using counselor training and collaborative programming strategies in working with international students. Journal of Multicultural Counseling and Development, 29(1), 73-88. http://dx.doi.org/10.1002/j.2161-1912.2001.tb00504.x 
Ku, L., Dittmar, H. \& Banerjee, R. (2014). To Have or to Learn? The Effects of Materialism on British and Chinese Children's Learning. Journal of Personality and Social Psychology, 106(5), 803-821. http://dx.doi.org/10.1037/a0036038

Lee, et al., (2004). Changing roles and values of female consumers in China. Business Horizons, 4(3), 17-22. http://dx.doi.org/10.1016/S0007-6813(04)00024-2

Li, J. (2009). Fostering citizenship in China's move from elite to mass higher education: An analysis of students' political socialization and civic participation. International Journal of Educational Development, 29(4), 382-398. http://dx.doi.org/10.1016/j.ijedudev.2008.10.001

Li, J., Canziani, B. \& Hsieh, Y. (2016). US and Chinese perceptions of simulated US courtesy. Worldwide Hospitality \& Tourism Themes, 8(1), 29-40. http://dx.doi.org/10.1108/WHATT-10-2015-0035

Li, N., Robson, A. \& Coates, N. (2013). Chinese consumers' purchasing: impact of value and affect. Journal of Fashion Marketing and Management: An International Journal, 17(4), 486 - 508. http://dx.doi.org/10.1108/JFMM-03-2013-0030

Liu, H., Liu, J. \& Chi, X. (2014). Regulatory mechanism of self-determination involvement in higher education: assessing Chinese students' experiences. Higher Education, 67, 51-70. http://dx.doi.org/10.1007/s10734-013-9640-x

Longerbeam, S. D., DeStefano, T. J. \& Yu, L. (2013). "We Cannot Reach Them": Chinese Undergraduate Student Perceptions of the U.S. Campus Climate. Journal of Student Affairs Research and Practice, 50(3), 326-344. http://dx.doi.org/10.1515/jsarp-2013-0023

Ma, J. (2013). Test preparation for high-stakes English language tests in China. Test Preparation. Research Newsletter, 5. Retrieved from Faculty of Education, Queen's University: http://educ.queensu.ca/sites/webpublish.queensu.ca.educwww/files/files/Research/Test $\% 20$

Ma, Y. McCabe, D. L. \& Liu, R. (2013). Students' Academic Cheating in Chinese Universities: Prevalence, Influencing Factors, and Proposed Action. Journal of Academic Ethics, 11, 169-184. http://dx.doi.org/10.1007/s10805-013-9186-7

Mori, J. \& Takeuchi, J. D. (2016). Campus Diversity and Global Education: A Case Study of a Japanese Program.Foreign Language Annals, 49(1), 146-161. http://dx.doi.org/10.1111/flan.12182

Muth, P. (2015).Already Guilty: Changing our perception of Chinese applicants. Journal of College Admission, 228, 47-50.

NAFSA: Association for International Educators, Open Door Data 2016, Special Reports: Economic Impact of International Students. Retrieved from http://www.iie.org/Research-and-Publications/Open-Doors/Data/Economic-Impact-of-International-Students

Özturgut, O. \& Murphy, C. (2010). Literature vs. Practice: Challenges for International Students in the U.S. International Journal of Teaching and Learning in Higher Education, 22(3), 374-385.

Pan, M. (2007). The Path to Popularizing Higher Education in China. Chinese Education and Society, 40(3), 92-100. http://dx.doi.org/10.2753/CED1061-1932400307

Park, J. (2012). Cultural Variations in the Self and Underlying Neural Mechanisms: Implications for Cognition, Emotion, and Motivation. (Unpublished doctoral dissertation). The University of Michigan.

Peng H. P. \& Chang, M. C. (2012). The foundations of Chines attitude towards advocating luxury spending. The European Journal of the History of Economic Thought, 19(5), 691-708. http://dx.doi.org/10.1080/09672567.2010.540342

Plänkers, T. (2011). Psychic Impact and Outcome of the Chinese Cultural Revolution (1966-1976). A Psychoanalytic Research Project at the Sigmund-Freud-Institut, Frankfurt (Germany). International Journal of Applied Psychoanalytic Studies, 8(3), 227-238. http://dx.doi.org/10.1002/aps.305

Poyrazli, S. \& Grahame, K. M. (2007). Barriers to Adjustment: Need of International Students within a Semi-Urban Campus Community. Journal of Instructional Psychology, 34 (1), 28-45.

Rajaram, K. (2013). Followers of Confucianism or a New Generation? Learning Culture of Mainland Chinese: In Pursuit of Western-Based Business Education Away from Mainland China. International Journal of Teaching and Learning in Higher Education, 25(3), 369-377.

Razek, N. \&Coyner, S. (2011). Behind the veil: cultural challenges and opportunities for a new international student group. Proceedings of the Academy of Educational Leadership, 16(2), 43-47. 
Redding, G. (1995). The Spirit of Chinese Capitalism. De Gruyter, Boston, MA.

Ross, H., Chen, Y. \& Zhou, Z. (2011). Assessing Student Engagement in China: Responding to Local and Global Discourse on Raising Educational Quality. Current Issues in Comparative Education, 14(1), 24-37.

Simon, A. et al., (2009). The Economics of Communist Party Membership: The Curious Case of Rising Numbers and Wage Premium during China's Transition. Journal of Development Studies, 45(2), 256-275. http://dx.doi.org/10.1080/00220380802264739

Sims, T. et al., (2015). Wanting to maximize the positive and minimize the negative: Implications for mixed affective experience in American and Chinese contexts.Journal of Personality and Social Psychology, 109 (2), 292-315. http://dx.doi.org/10.1037/a0039276

Tang, W. (2005). Public Opinion and Political Change in China. Stanford University Press, Stanford, CA.

Thakkar, D. (2011). Social \& Cultural Contexts on Chinese Learners Teaching Strategies for American Educators. Multicultural Education, 2011, 51-54.

The World Factbook (n.d.). Retrieved July 09, 2016, from https://www.cia.gov/library/publications/the-world-factbook/

Toshitaka, H. \& Laird, P. G. (2014). The Effect of Perfectionism and Acculturative Stress on Levels of Depression Experienced by East Asian International Students. Journal of Multicultural Counseling \& Development, 42 (4), 205-217. http://dx.doi.org/10.1002/j.2161-1912.2014.00055.x

Tsai, J. L. et al., (2016). Leaders' smiles reflect cultural differences in ideal affect. Emotion, 16 (2), 183-195. http://dx.doi.org/10.1037/emo0000133

Tu, Y. (2011). Citizenship with Chinese characteristics? An investigation into Chinese university students' civic perceptions and civic participation. Frontiers of Education in China, 6 (3), 426-448. http://dx.doi.org/10.1007/s11516-011-0140-4

Verstappen, S. H. (2015). Chinese Business Etiquette: The Practical Pocket Guide Revised and Updated. Berkeley, California: Stone Bridge Press.

Wang, Y. (2015). A Trend Study of the Influence of Parental Expectation, Parental Involvement, and Self-Efficacy on the English Academic Achievement of the Chinese Eight Graders. International Education, 44 (2), 45-68.

Walder, A. G. \& Sue, Y. (2003). Cultural Revolution in the Countyside; Scope, Timing and Human Impact. China Quarterly, 173, 74-99. http://dx.doi.org/10.1017/S0009443903000068

Wolff, M. \&Qiang, N. (2011). Lowdown on China's Higher Education. Newcastle upon Tyne: Cambridge Scholars Publishing.

Yan, K. \& Berliner, D. (2009). Chinese international students' academic stressors in the United States. College Student Journal, 43(4). 939-960.

Yan, K. \& Berliner, D. C. (2013). Chinese International students' Personal and Sociocultural Stressors in the United States. Journal of College Student Development, 54(1), 62-84. http://dx.doi.org/10.1353/csd.2013.0010

Yang, R. (2008). Transnational higher education in China: Contexts, Characteristics, and concerns. Australian Journal of Education, 52 (3), 272-286. http://dx.doi.org/10.1177/000494410805200305

Yao, C. W. (2016). Unfulfilled Expectations: Influence of Chinese International Students' Roommate Relationships on Sense of Belonging. Journal of International Students, 6 (3), 762-778.

Yin, H., Lu, G. \& Wang, W. (2014). Unmasking the teaching quality of higher education: students' course experience and approaches to learning in China, Assessment \& Evaluation in Higher Education, 39 (8), 949-970. http://dx.doi.org/10.1080/02602938.2014.880107

Yue, C. (2015). Expansion and equality in Chinese higher education. International Journals of Educational Development, 40, 50-58. http://dx.doi.org/10.1016/j.ijedudev.2014.11.017

Yu, W. \& Wang S. (2011). An Investigation into the Acculturation Strategies Of Chinese Students in Germany. Intercultural Communication Studies, 20(2), 190-210.

Afridi, F., Li, S. X. \& Ren, Y. (2015). Social identity and inequality: The impact of China's hukou system. Journal of Public Economics, 123 (2015), 17-29. http://dx.doi.org/10.1016/j.jpubeco.2014.12.011

Zhang, Z. \& Xu, J. (2007). Understanding Chinese international graduate students' adaptation to learning in North America: A cultural perspective. Higher Education Perspectives, 3(1), 45-59. 